\title{
Trends and associated factors of alcohol consumption among Southern Thai adolescents, 2003-2009
}

\author{
Nopporn Tantirangsee ${ }^{1}$, Sawitri Assanangkornchai ${ }^{2}$, and Alan F. Geater ${ }^{2}$ \\ ${ }^{1}$ Songkhla Rajanagarindra Psychiatric Hospital, Muang, Songkhla, Thailand \\ ${ }^{2}$ Faculty of Medicine, Prince of Songkla University, Hat Yai, Songkhla, Thailand
}

\section{Abstract}

Aims: To examine the trends in and the factors associated with the use of alcohol among high school students during the period from 2003 to 2009 in southern Thailand.

Design: School-based biannual cross-sectional surveys. A self-administered, voluntary and anonymous questionnaire was used to collect data on current alcohol drinking and demographic variables. The time trends were evaluated using a Chi-squared test for trend. The factors associated with alcohol consumption were examined by survey logistic regression models.

Setting: High school student sample in southern Thailand.

Participants: Grade 7, 9 and 11 students. The numbers of students sampled were 10,972, 9,005, 6,097 and 5,573 in 2003, 2005, 2007 and 2009, respectively.

Measures: The association of the use of alcohol over a 30-day period with year of survey and demographic variables including gender, school level, school location, GPA and religion.

Findings: Prevalence of the use of alcohol over a 30-day period in grade 11 students tended to increase in males ( $p$-value $<$ 0.001 ) with no change in females, but the trends of drinking in younger students (grades 7 and 9 ) decreased over the years in both genders ( $p$-value < 0.001). Male gender (OR 2.16, 95\% CI 1.91-2.44), higher school years (grade 9: OR 2.66, 95\% CI 2.35-3.01 and grade 11: OR 2.93, 95\% CI 2.41-3.55), Buddhism (OR 3.50, 95\% CI 2.65-4.64) and low school record (OR 1.51, 95\% CI 1.30-1.75) were variables associated with alcohol consumption.

Conclusions: The prevalence of young drinkers decreased over the years covered in this study, although the prevalence among senior high school students increased. Specific interventions should be designed and integrated in school activities to reduce the prevalence of alcohol consumption.

Alcohol is a leading public health problem worldwide. Each year 2.5 million people die as a result of harmful drinking, 320,000 of whom are between 15 and 29 years old (World Health Organization, 2011a). In 2010, alcohol was the fifth leading cause of attributable global burden of disease worldwide (Lim et al., 2012) and one of the leading behavioral risk factors of noncommunicable diseases in low- and middle-income countries (World Health Organization, 2011b).

Thailand is a middle-income country in which alcohol was estimated to cause a net harm of $7.5 \%$ of the total burden of disease in 2009 (International Health Policy Program, 2012). It was the topmost risk factor for disability adjusted life years (DALY) lost in Thailand after HIV was successfully brought under control in 2002. The top causes of death in young people aged 15 to 29 were traffic accidents, homicide and violence, HIV/AIDS, and suicide (International Health Policy Program, 2012). It is believed that alcohol may play an important role in these losses, yet its exact contribution is not fully understood.

Several alcohol control policies have been formulated since the establishment, in 2001, of the Thai Health Promotion Foundation (ThaiHealth) (Buasai, Kanchanachitra, \& Siwaraksa, 2007). With ThaiHealth's support, the Stop Drink Network was established in 2003 as a coordinating body for individuals and groups who share concerns about alcohol issues, and the Center for Alcohol Studies (CAS) was established in 2004 as a national research institute for the reduction of alcohol-related harms (Thamarangsi, 2013). Several media campaigns were developed

Correspondence: Sawitri Assanangkornchai. Epidemiology Unit, Faculty of Medicine, Prince of Songkla University, 15 Kanchanavanich Road, Hat Yai, Songkhla 90110, Thailand. Telephone: +6674451165; Fax: +6674429754; E-mail: savitree.a@psu.ac.th

Financial support: Thailand Center for Alcohol Studies, Thai Health Promotion Foundation Institute of Research and Development for Health of Southern Thailand Prince of Songkla University Research Fund

Keywords: trend, alcohol consumption, adolescent, southern Thai 
specifically to counteract the advertisements of the alcohol industry and increase people's awareness of the harm related to drinking. The alcohol taxation system currently used in Thailand, "Two-chosen-One," which combines alcohol-specific taxation and ad valorem taxation, may be an effective way to reduce alcohol consumption and prevent drinking initiation among youth (Sornpaisarn, Shield, \& Rehm, 2012). In 2008, the Alcoholic Beverage Control Act was promulgated. This law has several sections specifically aimed at restricting adolescents' access to alcohol, by increasing the minimum legal age for purchasing alcoholic beverages to 20 years; prohibiting the sale of alcoholic beverages in educational institutes and dormitory areas; prohibiting advertisements of alcoholic beverages that are deemed to exaggerate the products' qualities or induce people to drink; and restricting hours of sale to 11 a.m. to 2 p.m. and 5 p.m. to 12 p.m. (Alcoholic Beverage Control Laws, 2008).

Despite the large number of alcohol policies formulated to prevent underage drinking, the empirical outcome of these measures has been limited. A series of repeated surveys among high-school students in southern Thailand was initiated in 2002 and conducted annually for four years, with the aim of following the trends of alcohol and substance use and other health-risk behaviors among youth (Assanangkornchai, Pattanasattayawong, Samangsri, \& Mukthong, 2007). In 2007 and 2009, it was expanded into a national school survey, which initially was meant to be carried out biannually to assess the country-wide impact of underage drinking and related prevention and control activities (Assanangkornchai, Mukthong, \& Intanont, 2009). This study aims to examine the six-year trends and the factors associated with alcohol consumption over a 30day period among high-school students between 2003 and 2009 in southern Thailand. Information about trends in underage drinking at the regional level could indirectly reflect the outcome of the control strategies, and knowledge of the factors associated with alcohol consumption is important for planning further policies and interventions for health promotion and for prevention of the harmful effects of alcohol consumption in youths.

\section{Methods}

\section{Setting}

The data were derived from a series of repeated surveys on drinking behaviors and other health-risk behaviors among high-school students in southern Thailand in 2003, 2005, 2007 and 2009. The first two surveys were exclusive to southern Thailand; for the latter two, data for this southern region were retrieved from surveys conducted throughout the country. The primary sampling unit (PSU) was the province in southern Thailand, and the secondary sampling units (SSUs) were the schools in each province. The number of randomly selected provinces was four, eight, seven and seven in 2003, 2005, 2007 and 2009 respectively, representative of 14 provinces in the south. Twenty-nine to 31 public and private schools in urban and rural areas of each selected province were randomly selected. The participants were grade 7, 9 and 11 students in normal stream education (the normal ages of grades 7, 9 and 11 students in Thailand are 12 to 13,14 to 15, and 16 to 17 years, respectively). In each school, all classes in each school level were recruited if there were five classes or fewer. If there were more than five classes, three classes were randomly selected. The participants were all students in the classes. The number of students sampled was 10,972, 9,005, 6,097 and 5,573 in 2003, 2005, 2007 and 2009, respectively. The survey was undertaken between June and August of each year. Students were informed about the objectives of the survey and of their right to decline to participate. The total participation rate was as high as $99 \%$ in each survey. The project was approved by the Ethics Committee for Research in Human Subjects of the Faculty of Medicine, Prince of Songkla University. Details of the survey methods were published elsewhere (Assanangkornchai et al., 2007; Assanangkornchai et al., 2009).

\section{Questionnaire and variables}

A self-administered, voluntary and anonymous questionnaire was used to collect data during a regular class period. The questionnaire had 100 questions and took 40 to 50 minutes to finish. The data on current alcohol drinking (defined as having drunk at least one standard drink in the previous 30 days) and the demographic variables, including year of data collection, gender, school level, grade point average (GPA) in the previous semester, school location (rural or urban) and religion, from each year of the surveys, were used for the analysis.

\section{Statistical analysis}

The sampling weight for the two-stage stratified sampling technique was calculated based on the statistics of schools and students from the National Office of the Basic Education Commission (Office of the Basic Education Commission, 2012). The weights for the PSU and SSUs were the inverse probability of the provinces and students being selected in each year; and the total weight of the students was the multiplication of the weights for PSU and SSUs in each gender in the particular year. A Chi-squared test was used to evaluate the time trend. A missing value for the question regarding history of alcohol use in the past 30 days was treated as a "no", (i.e., as the respondent not having used alcohol in the previous 30 days). All missing values in the demographic variables were imputed using the median of each variable. Survey logistic regression modeling was used to examine the association between use of alcohol in past 30 days and year of survey, school location, and student's demographic variables including gender, school level, GPA and religion (model 1). The linear associations between alcohol use in the past 30 days and year of survey were tested by treating categorized year of survey as a continuous variable of $0,1,2,3$ (zeroed on 2003) in model 1 (model 2). The effect of the Alcoholic Beverage Control Law was evaluated using the variable representing before and after introduction of this law (before and after year 2008) in model 2 to control for underlying trend. The Wald test was used to test the hypothesis that coefficient is zero, while the likelihood ratio test was used to test the significance of the 
contribution of each variable to the fit of the model. Statistical significance was defined as $p$-value $<0.05$. The terms representing the interactions of year of survey and gender and the interactions of year of survey and religion were included in subsequent models to test for differences in the association between alcohol use in the past 30 days and the different gender and religion in each year of the survey. The statistical analysis was done in $\mathrm{R}$ software version 2.15.0 (R Core Team, 2012).

\section{Results}

\section{Sample characteristics}

Table 1 displays the characteristics of the student samples in each year of the survey. The distributions of students by gender, age and school level were similar in all years. The number of students in rural areas in 2003 was higher than that in the other years. The GPA tended to decrease in the last two surveys. A higher proportion of Muslim students was found in 2009 than in the other years.

\section{Trends of alcohol consumption}

Table 2 shows the decreasing trends of alcohol consumption in both genders over years. Stratified by school year, the prevalence of drinking significantly decreased over time in grade 7 and 9 students. However, a significantly increasing trend was found among grade 11 male students, while there was no change in females.

Factors associated with alcohol use in past 30 days Table 3 shows that the year of survey, gender, school level, school performance and religion were significantly associated with current drinking. Odds of drinking significantly decreased on average $17 \%$ every two years. Male students were twice more likely to drink alcohol than female students. Students in higher school levels and those who had lower school performances had higher use of alcohol. Buddhists were over three times more likely to report alcohol drinking than Muslims and those of other religions. The prevalence of alcohol use was not significantly changed between before and after the Alcoholic Beverage Control Law was enacted in 2008. The interactions between year of survey versus gender and religion group were tested but not found to be significant (alpha $=0.05$ level).

\section{Table 1}

Number of selected provinces and schools and sample characteristics in each year of survey

\begin{tabular}{|c|c|c|c|c|}
\hline & \multicolumn{4}{|c|}{$n(\%)^{a}$} \\
\hline & $2003\left(N^{b}=10,972\right)$ & $2005\left(N^{b}=9,005\right)$ & $2007\left(N^{b}=6,097\right)$ & $2009\left(N^{b}=5,573\right)$ \\
\hline Selected provinces & 4 & 8 & 7 & 7 \\
\hline Selected school & 31 & 31 & 29 & 31 \\
\hline \multicolumn{5}{|l|}{ Gender } \\
\hline Male & $5,151(46.9)$ & $3,829(42.5)$ & 2,428 (39.8) & 2,323 (41.7) \\
\hline Female & $5,821(53.1)$ & $5,176(57.5)$ & $3,669(60.2)$ & $3,250(58.3)$ \\
\hline \multicolumn{5}{|l|}{ Age } \\
\hline Mean + S.D. & $14.24+1.65$ & $14.49+1.7$ & $14.75+1.73$ & $14.78+1.74$ \\
\hline \multicolumn{5}{|l|}{ School level } \\
\hline Grade 7 & 4,432 (40.4) & $3,254(36.1)$ & $2,146(35.2)$ & $2,156(38.7)$ \\
\hline Grade 9 & 4,051 (36.9) & 3,185 (35.4) & $2,209(36.2)$ & $1,827(32.8)$ \\
\hline Grade 11 & 2,489 (22.7) & 2,566 (28.5) & 1,742 (28.6) & $1,590(28.5)$ \\
\hline \multicolumn{5}{|l|}{ School location } \\
\hline Rural & 6,492 (59.2) & 3,836 (42.6) & $2,542(41.7)$ & 2,689 (48.3) \\
\hline Urban & $4,480(40.8)$ & $5,169(57.4)$ & 3,555 (58.3) & $2,884(51.7)$ \\
\hline \multicolumn{5}{|l|}{ GPA } \\
\hline Mostly A or B & 6,788 (61.9) & $5,773(64.1)$ & 2,176 (35.7) & $1,886(33.8)$ \\
\hline Mostly C & 2,859 (26.0) & 2,135 (23.7) & 2,089 (34.3) & 2,110 (37.9) \\
\hline Mostly D or less & $1,325(12.1)$ & $1,097(12.2)$ & $1,832(30.0)$ & $1,577(28.3)$ \\
\hline \multicolumn{5}{|l|}{ Religion } \\
\hline Buddhism & $8,180(74.6)$ & 7,105 (78.9) & 4,691 (76.9) & $3,470(62.3)$ \\
\hline Islam \& Others & 2,792 (25.4) & $1,900(21.1)$ & $1,406(23.1)$ & 2,103 (37.7) \\
\hline
\end{tabular}

a Percentage by column based on unweighted data.

${ }^{\mathrm{b}}$ Indicates total number of students of that category. 
Table 2

Weighted 30-day prevalence (95\% Confidence Interval) of alcohol consumption by survey years, gender and school level

\begin{tabular}{|c|c|c|c|c|c|c|}
\hline Level & 2003 & 2005 & 2007 & 2009 & $X^{2}$ & p-value \\
\hline \multicolumn{7}{|l|}{ Male } \\
\hline Grade 7 & $14.0(12.6-15.4)$ & $11.4(8.8-13.9)$ & $6.9(4.2-9.6)$ & $8.9(6.2-11.6)$ & 1094.1 & $<0.001$ \\
\hline Grade 9 & $29.4(25.1-33.8)$ & $24.4(17.8-30.9)$ & $26.2(11.3-41.0)$ & 17.9 (16.0-19.9) & 854.0 & $<0.001$ \\
\hline Grade 11 & $24.9(11.9-38.0)$ & 32.8 (23.3-42.3) & 27.3 (16.3-38.3) & $32.6(26.8-38.4)$ & 102.0 & $<0.001$ \\
\hline Total & $20.3(14.9-25.8)$ & $18.1(13.9-22.1)$ & 15.7 (9.3-22.1) & $13.6(11.5-15.6)$ & 1660.1 & $<0.001$ \\
\hline \multicolumn{7}{|l|}{ Female } \\
\hline Grade 7 & $9.0(7.0-11.0)$ & $4.8(2.8-6.7)$ & $3.6(0.16-7.0)$ & $3.0(1.7-4.2)$ & 1952.0 & $<0.001$ \\
\hline Grade 9 & $17.9(14.6-21.2)$ & 11.2 (8.6-13.7) & $11.5(0.04-23.1)$ & $10.2(5.6-14.8)$ & 1354.6 & $<0.001$ \\
\hline Grade 11 & $14.8(9.6-20.0)$ & $9.5(6.6-12.4)$ & $15.6(5.6-25.7)$ & $12.4(9.2-15.6)$ & 0.3 & 0.567 \\
\hline Total & $14.1(10.9-17.2)$ & 8.7 (6.5-10.8) & $9.9(0.1-18.9)$ & $9.0(11.5-15.6)$ & 1522.6 & $<0.001$ \\
\hline \multicolumn{7}{|l|}{ Both Gender } \\
\hline Grade 7 & 11.7 (10.1-13.4) & $7.7(5.8-9.7)$ & $4.9(1.4-8.4)$ & $6.1(4.4-7.8)$ & 2889.3 & $<0.001$ \\
\hline Grade 9 & $22.0(18.8-25.2)$ & 15.1 (12.1-18.2) & $15.9(2.8-29.0)$ & 12.7 (9.6-15.8) & 2346.5 & $<0.001$ \\
\hline Grade 11 & 17.9 (11.3-24.4) & 12.8 (9.6-16.1) & $17.1(7.8-26.4)$ & 14.3 (10.4-18.1) & 94.2 & $<0.001$ \\
\hline Total & 16.7 (13.9-19.5) & $11.7(9.3-14.2)$ & $11.7(3.2-20.1)$ & $10.5(8.7-12.4)$ & 3869.8 & $<0.001$ \\
\hline
\end{tabular}

$Z^{2}=$ Chi-squared test for trend in proportions.

Table 3

Adjusted $^{a}$ Odds Ratios (AORs) and 95\% Confidence Intervals (95\% CI) of factors associated with alcohol use in the past 30 days

\begin{tabular}{|c|c|c|c|c|c|c|}
\hline \multirow[b]{2}{*}{ Variable } & \multicolumn{2}{|c|}{ Alcohol use in past 30 days } & \multirow[b]{2}{*}{$A O R$} & \multirow[b]{2}{*}{$95 \% \mathrm{CI}$} & \multirow[b]{2}{*}{$P$ (Wald test) } & \multirow[b]{2}{*}{$P\left(\right.$ LR-test $\left.^{b}\right)$} \\
\hline & No (\%) & Yes (\%) & & & & \\
\hline Year & & & & & & 0.222 \\
\hline 2003 & 9095 (82.9) & $1877(17.1)$ & 1 & & & \\
\hline 2005 & 7927 (88) & $1078(12)$ & 0.63 & $0.50-0.78$ & 0.025 & \\
\hline 2007 & $5374(88.1)$ & 723 (11.9) & 0.59 & $0.33-1.07$ & 0.183 & \\
\hline 2009 & $4909(88.1)$ & $664(11.9)$ & 0.59 & $0.46-0.76$ & 0.026 & \\
\hline Trend/ 2 years ${ }^{c}$ & & & 0.83 & $0.78-0.89$ & 0.003 & 0.004 \\
\hline Gender & & & & & & $<0.001$ \\
\hline Female & $16202(90.4)$ & $1714(9.6)$ & 1 & & & \\
\hline Male & 11103 (80.9) & $2628(19.1)$ & 2.16 & $1.91-2.44$ & 0.001 & \\
\hline School level & & & & & & $<0.001$ \\
\hline Grade 7 & $11038(92.1)$ & $950(7.9)$ & 1 & & & \\
\hline Grade 9 & $9373(83.2)$ & $1899(16.8)$ & 2.66 & $2.35-3.01$ & $<0.001$ & \\
\hline Grade 11 & $6894(82.2)$ & $1493(17.8)$ & 2.93 & $2.41-3.55$ & 0.001 & \\
\hline \multicolumn{7}{|l|}{ School location } \\
\hline Rural & $13407(86.2)$ & $2152(13.8)$ & 1 & & & 0.532 \\
\hline Urban & $13898(86.4)$ & $2190(13.6)$ & 1.06 & $0.90-1.25$ & 0.534 & \\
\hline GPA & & & & & & 0.005 \\
\hline Mostly A or B & $14870(89.5)$ & $1753(10.5)$ & 1 & & & \\
\hline Mostly C & 7504 (81.6) & $1689(18.4)$ & 1.49 & $1.31-1.69$ & 0.009 & \\
\hline Mostly D or less & 4931 (84.6) & $900(15.4)$ & 1.51 & $1.30-1.75$ & 0.013 & \\
\hline Religion & & & & & & $<0.001$ \\
\hline Islam and Others & 7755 (94.6) & 446 (5.4) & 1 & & & \\
\hline Buddhism & 19550 (83.4) & 3896 (16.6) & 3.52 & $2.66-4.65$ & 0.003 & \\
\hline $\begin{array}{l}\text { Effect from Alcoholic Beverage } \\
\text { Control Law (2008) }{ }^{c}\end{array}$ & & & & & & 0.456 \\
\hline Before enactment & 22396 (85.9) & $3678(14.1)$ & 1 & $0.60-3.53$ & & \\
\hline After enactment & 4909 (88.1) & $664(11.9)$ & 1.45 & & & \\
\hline
\end{tabular}

${ }^{\text {a }}$ Adjusted for year of survey, gender, school level, school location, GPA and religion; ${ }^{\mathbf{b}}$ Likelihood-ratio test.

${ }^{\mathbf{c}}$ Result from model 2 by treating year of survey as a continuous variable coded as 0, 1, 2, 3 (zeroed on 2003). 


\section{Discussion}

This study aimed to find the trends and factors associated with alcohol consumption among students in southern Thailand from 2003 to 2009. We observed that the prevalence of students reporting alcohol consumption in the previous 30 days significantly decreased from 2003 to 2009 among students in grades 7 to 11 in southern Thailand. Additionally, we found that year of the survey, gender, school grade level, GPA, and religion were all significantly associated with the odds of alcohol use in the past 30 days, whereas school location and the implementation of the Alcohol Beverage Control Act in 2008 were not associated with alcohol consumption in the past 30 days.

Decreasing trends of drinking among youths have also been found in high-income countries. In the U.S., the prevalence of youth aged 12 to 20 who reported consuming alcohol in the past 30 days decreased from $33.4 \%$ in 1991 to $27.1 \%$ in 2009 (Chen, Yi, \& Faden, 2011); the percentage of grade 10 students in Canada who reported consuming beer at least once a month decreased from 44\% in 1990 to $28 \%$ in 2006 (Elgar, Phillips, \& Hammond, 2011); the lifetime prevalence of alcohol use in secondary school pupils aged 11 to 15 in England dropped from $61 \%$ in 2001 to $45 \%$ in 2011 (O'Dowd, 2012); the number of non-drinkers among seventh and ninth grade students in Finland increased from $44 \%$ to 63\% between the years 1998 and 2008 (Sourander et al., 2012); and the monthly drinking rate among senior high school students in Japan decreased from $49.7 \%$ to $36.2 \%$ in boys, and from $40.8 \%$ to $34.1 \%$ in girls, from 1996 to 2004 (Osaki et al., 2009). However, in the Netherlands, another high-income country, the prevalence of drinking a few times a month among 12- to 15-year-olds increased from $14.2 \%$ to $41.9 \%$ among males, and $9.8 \%$ to 31.9\% among females, from 1990 to 2000 (Poelen, Scholte, Engels, Boomsma, \& Willemsen, 2005).

Turning to middle-income countries, the lifetime alcohol use among youth in South Africa between 1998 and 2008 remained stable at 49.1 to $49.6 \%$ (Ramsoomar \& Morojele, 2012), while in Lithuania the number of students aged 11 to 15 who had been drunk two or more times increased by 2.5 times (from $9.8 \%$ to $25.6 \%$ ) during the period from 1994 to 2006 (Zaborskis et al., 2008).

In our study, the prevalence of alcohol use in the past 30 days in males was found to be decreasing by around $11 \%$ to $13 \%$ each year $(20.34 \%, 18.05 \%, 15.68 \%$ and $13.56 \%$ in 2003, 2005, 2007 and 2009, respectively). In females, it dropped markedly from 2003 (14.08\%) to 2005 (8.65\%), but thereafter changed only slightly $(9.93 \%$ and $8.96 \%$ in 2007 and 2009, respectively). All surveys have shown that the prevalence of alcohol use in males in the previous 30 days was higher than in females, for all school levels. This gender difference has been ascribed to the perception that alcohol use is a symbol of manliness (Eriksen, 1999) and has greater social acceptance than alcohol use by females (Jakobsson, Hensing, \& Spak, 2008). This phenomenon is true of Thailand and is also very widespread globally (Ahlstrom \& Osterberg, 2004). However, we found that the discrepancy in drinking prevalence between males and females tended to be smaller in the later years. Compared to data in a report on alcohol consumption among the general population in 2007, in which the prevalence of drinking, in males and females respectively, was $58.5 \%$ and $15.6 \%$ among 25 - to 44 -year-olds and $48.8 \%$ and $11.0 \%$ among 45- to 65-year-olds (Assanangkornchai, SamAngsri, Rerngpongpan, \& Lertnakorn, 2010), the gender gap in these students was markedly small. The narrowing gap between genders was not only found in Thailand but also worldwide (Simons-Morton et al., 2009). One reason might be that nowadays, the marketing strategies of the alcohol industry are targeting females. For example, new products with low alcohol concentration, in colorful and alluring containers, have been introduced to the market to attract women (Mart, 2011). Strategies to counteract the commercial availability and marketing of these beverages should be seriously and urgently considered, before they further increase the social availability of alcohol and contribute to changing social and cultural norms that promote drinking among Thai female youths.

Although the overall trend of alcohol use in the past 30 days was decreasing, it was found to be rising among males in the senior year of high school (Grade 11) and not significantly changing in females in grade 11 . This may be because senior students were able to obtain alcohol more easily than younger students and were more exposed to peer influence (Spear \& Kulbok, 2001).

The highest odds of alcohol use were found in the group with the poorest school performance. There are three potential explanations for this: First, alcohol might cause poor school performance, because students may fail to attend to their studies after alcohol use (Aspy et al., 2012), and because of the effect of alcohol on the hippocampus, the brain area responsible for learning memory (Morris, Eaves, Smith, \& Nixon, 2010). Second, students may be using alcohol as a way to cope with the distress caused by poor school achievement (Hayatbakhsh, Najman, Bor, Clavarino, \& Alati, 2011). It may be the case that both of these explanations are true, and causality is operating in two directions simultaneously. A third possibility is that both alcohol use and poor school performance are the consequences of other conditions, such as depression (Glied \& Pine, 2002).

Muslims have a lower prevalence of alcohol consumption than Buddhists, who make up the majority of Thai people. In fact, Islam strictly prohibits alcohol drinking, and this is reflected in our finding that Buddhist students were 3.52 times more likely to drink alcohol.

Although the Alcohol Beverage Control Law-which restricts the availability of alcohol, especially to youthswas promulgated in Thailand in 2008, at the time of our study people were not yet generally aware of these regulations, as they were only later enacted (Sornpaisarn, Kaewmungkun, \& Wattanaporn, 2010). This may explain why there was no significant change in alcohol use in adolescents after the promulgation of this law. Subsequent surveys should be conducted to see whether, over time, the 
law does have any effect on youths' access to alcohol and consequent drinking.

The strength of this study is that it is the first reliable trend report on alcohol use in the past 30 days in Thai adolescents, because the data were derived from repeated surveys that were done by the same investigators using the same questionnaire. The samples were also large in each year of survey.

Nevertheless, the study has some limitations. Because it analyzed secondary data from cross-sectional studies, causal relationships among the data could not be clearly identified, and recall bias could not be avoided. The data came from two different sampling frames, because the first two surveys were done only in southern Thailand but the latter two were done throughout the country. Sample weighting was used to minimize this limitation. The distributions of some sample characteristics, such as GPA and religion, were not the same in all surveys, but these variables were adjusted for in the regression model. Underage drinking in Thailand is illegal and not socially accepted; therefore, responses concerning history of alcohol use may have been subject to social desirability response bias and drinking may have been underreported (van de Mortel, 2008). To lessen this effect, a selfadministered anonymous questionnaire was used. The outcome variable in this study focused on prevalence of alcohol use in the past 30 days, but did not capture the amount of alcohol consumed among student drinkers; therefore, the measure of quantity of drinking might be limited. Since the surveys were done within the educational system, the result cannot be generalized to teenagers outside the school system. The proportion of Muslims among the Thai population is highest in southern Thailand, and alcohol drinking is strongly prohibited for them. Therefore, generalizability to the whole country might be limited.

In conclusion, reported alcohol use in past 30 days among students in southern Thailand between 2003 and 2009 showed a decreasing trend overall, especially in the younger age groups, but increased in the older age group. Drinking status differed across gender, school level, GPA and religion. These results reflect the multi-domain nature of the problem and the need for specific interventions to be integrated into the school curriculum to decrease the prevalence of alcohol use. The yearly surveys should continue to be administered, to measure the magnitude of the problems after the interventions are integrated.

\section{Acknowledgement}

The study is part of the first author's qualifying examination in partial fulfillment of the requirements for a Ph.D. at Prince of Songkla University, Thailand, which is supported by the Royal Golden Jubilee Ph.D. Program scholarship. The school surveys were funded by the Center for Alcohol Studies, Thai Health Promotion Foundation, Institute of Research and Development for Health of Southern Thailand, and the Prince of Songkla University
Research Fund. The Epidemiology Unit, Prince of Songkla University, is partially supported by the National Science and Technology Development Agency, Ministry of Science and Technology, Thailand.

\section{References}

Ahlstrom, S. K., \& Osterberg, E. L. (2004). International perspectives on adolescent and young adult drinking. Alcohol Research \& Health, 28, 258-268.

Aspy, C. B., Vesely, S. K., Oman, R. F., Tolma, E., Rodine, S., Marshall, L., \& Fluhr J. (2012). Schoolrelated assets and youth risk behaviors: Alcohol consumption and sexual activity. Journal of School Health, 82, 3-10.

Assanangkornchai, S., Mukthong, A., \& Intanont, T. (2009). Prevalence and patterns of alcohol consumption and health-risk behaviors among high school students in Thailand. Alcoholism: Clinical and Experimental Research, 33, 2037-2046.

Assanangkornchai, S., Pattanasattayawong, U., Samangsri, N., \& Mukthong, A. (2007). Substance use among high-school students in Southern Thailand: Trends over 3 years (2002-2004). Drug and Alcohol Dependence, 86, 167-174.

Assanangkornchai, S., Sam-Angsri, N., Rerngpongpan, S., \& Lertnakorn, A. (2010). Patterns of alcohol consumption in the Thai population: Results of the National Household Survey of 2007. Alcohol and Alcoholism, 45, 278-285.

Buasai, S., Kanchanachitra, C., \& Siwaraksa, P. (2007). The way forward: Experiences of health promotion development in Thailand. Promotion \& Education, 14, 250-253.

Chen, C. M., Yi, H. Y., \& Faden, V. B. (2011). Surveillance report \#86: Trends in underage drinking in the United States, 1991-2009. Bethesda, MD, United States: National Institute on Alcohol Abuse and Alcoholism.

Elgar, F. J., Phillips, N., \& Hammond, N. (2011). Trends in alcohol and drug use among Canadian adolescents, 1990-2006. Canadian Journal of Psychiatry, 56, 243247.

Eriksen, S. (1999). Alcohol as a gender symbol. Scandinavian Journal of History, 24, 45-73.

Glied, S. \& Pine, D. S. (2002). Consequences and correlates of adolescent depression. Archives of Pediatrics and Adolescent Medicine, 156, 1009-1014.

Hayatbakhsh, M. R., Najman, J. M., Bor, W., Clavarino, A., \& Alati, R. (2011). School performance and alcohol use problems in early adulthood: A longitudinal study. Alcohol, 45, 701-709.

International Health Policy Program (IHPP), Thailand (2012). Thailand Burden of Disease (BOD) 2009. Retrieved from http://www.thaibod.net/

Jakobsson, A., Hensing, G., \& Spak, F. (2008). The role of gendered conceptions in treatment seeking for alcohol problems. Scandinavian Journal of Caring Science, 22, 196-202.

Lim, S. S., Vos, T., Flaxman, A. D., Danaei, G., Shibuya, K., Adair-Rohani, H., ... Memish Z. A. (2012). A 
comparative risk assessment of burden of disease and injury attributable to 67 risk factors and risk factor clusters in 21 regions, 1990-2010: A systematic analysis for the Global Burden of Disease Study 2010. Lancet, 380, 2224-2260.

Mart, S. M. (2011). Alcohol marketing in the 21st century: New methods, old problems. Substance Use \& Misuse, 46, 889-892.

Morris, S. A., Eaves, D. W., Smith, A. R., \& Nixon, K. (2010). Alcohol inhibition of neurogenesis: A mechanism of hippocampal neurodegeneration in an adolescent alcohol abuse model. Hippocampus, 20, 596-607.

O'Dowd, A. (2012). Drug taking and drinking among 1115-year-olds in England have fallen over past 10 years. British Medical Journal, 345, e5153.

Office of the Basic of Education Commission (2012). Education Statistics in Brief. Retrieved from http://www.moe.go.th/data_stat/

Office of the Council of State. (2008). Alcoholic Beverage Control Laws. In The Royal Decree: Vol. 125 (pp. 3448). Bangkok: Cabinet Publishing and Gazzette Office.

Osaki, Y., Tanihata, T., Ohida, T., Kanda, H., Suzuki, K., Higuchi, S., .. . Hayashi K. (2009). Decrease in the prevalence of adolescent alcohol use and its possible causes in Japan: Periodical nationwide cross-sectional surveys. Alcoholism: Clinical and Experimental Research, 33, 247-254.

Poelen, E. A., Scholte, R. H., Engels, R. C., Boomsma, D. I., \& Willemsen, G. (2005). Prevalence and trends of alcohol use and misuse among adolescents and young adults in the Netherlands from 1993 to 2000. Drug and Alcohol Dependence, 79, 413-421.

R Core Team (2012). R: A language and environment for statistical computing. R Foundation for Statistical Computing, Vienna, Austria. Retrieved from http://www.R-project.org/

Ramsoomar, L., \& Morojele, N. K. (2012). Trends in alcohol prevalence, age of initiation and association with alcohol-related harm among South African youth: Implications for policy. South African Medical Journal, 102, 609-612.

Simons-Morton, B. G., Farhat, T., ter Bogt, T. F., Hublet, A., Kuntsche, E., Nic, G. S. . . Kokkevi, A. (2009). Gender specific trends in alcohol use: cross-cultural comparisons from 1998 to 2006 in 24 countries and regions. International Journal of Public Health, 54 Suppl 2, 199-208.

Sornpaisarn B, Kaewmungkun J, \& Wattanaporn K (2010). Thailand Annual Report on Alcohol 2010. Nonthaburi: Center for Alcohol Studies.

Sornpaisarn, B., Shield, K. D., \& Rehm, J. (2012). Alcohol taxation policy in Thailand: Implications for other low- to middle-income countries. Addiction, 107, 1372-1384.

Sourander, A., Koskelainen, M., Niemela, S., Rihko, M., Ristkari, T., \& Lindroos, J. (2012). Changes in adolescents mental health and use of alcohol and tobacco: A 10-year time-trend study of Finnish adolescents. European Child \& Adolescent Psychiatry, $21,665-671$.
Spear, H. J., \& Kulbok, P. A. (2001). Adolescent health behaviors and related factors: A review. Public Health Nursing, 18, 82-93.

Thamarangsi, T. (2013). Addiction research centres and the nurturing of creativity: Center for Alcohol Studies (CAS), Thailand. Addiction, 108, 1201-1206.

van de Mortel, T. F. (2008). Faking it: Social desirability response bias in self-report research. Australian Journal of Advanced Nursing, 25, 40-48.

World Health Organization (2011a). Alcohol Fact sheet. Retrieved from http:/www.who.int/mediacentre/ factsheets/fs349/en/index.html

World Health Organization (2011b). Global status report on noncommunicable diseases 2010. Italy: WHO Press.

Zaborskis, A., Zemaitiene, N., Sumskas, L., Grabauskas, V., Veryga, A., \& Petkevicius, R. (2008). Trends in alcohol consumption among Lithuanian school-aged children in 1994-2006 and new challenges. Medicina (Kaunas, Lithuania), 44, 623-632. 